\title{
Creating Positive Learning Environments in Early Childhood Using Teacher-Generated Prosocial Lessons
}

\author{
Callum B. Johnston \\ Francis Marion University \\ Teresa K. Herzog \\ Francis Marion University \\ Crystal R. Hill-Chapman \\ Francis Marion University \\ Caitlin Siney \\ Francis Marion University \\ Ashley Fergusson \\ Francis Marion University
}

\begin{abstract}
A primary motivation for people to behave as they do is the need to belong socially to a group and to have relevance. A positive learning environment for young students is created when students are recognized and accepted by their peers and their teachers, and studies reveal that in such environments, students perform better academically and tend to have fewer behavioral issues. These environments may also act as a buffer against school dropout rates. This study examined whether teaching prosocial lessons to first-grade students in the southeastern United States would create positive learning environments for children who otherwise may not be recognized and accepted by their peers and also examined the relationship of teacher evaluations of observable classroom behaviors by their students with student recognition by peers. This study confirms the relevance of prosocial lessons in the creation of positive learning environments for young students.
\end{abstract}

Keywords: young children, early childhood education, elementary education, prosocial education, social development

\section{Introduction}

It is well documented that positive emotion in regard to academics is a strong predictor of school success, with higher, versus lower, levels predicting high executive functioning and academic achievement (Lewis, Huebner, Malone, \& Valois, 2011; Li \& Lerner, 2011; Pekrun, Goetz, Titz, \& Perry, 2002; Villavicencio \& Bernardo, 2013). Positive emotion has been identified by Piff and Moskowitz (2018) as emotions of joy, love, pride, and happiness. Pride, one element of positive emotion, involves the evaluation of self as compared to others in terms of socially valued behaviors and accomplishment (Cohen \& Huppert, 2018), and there exists evidence that both positive and negative emotions have an impact on cognitive processes (Madan, Scott, \& Kensinger, 2019). These relations hold whether the positive emotion relates to self, school, or an academic task (Mega, Ronconi, \& De Beni, 2014). Moreover, positive emotions have been shown to enhance self-perceptions of ability to learn, preparation to learn, as well as metacognitive self-regulation during learning (Chen et al., 2018; Pekrun, Lichtenfield, Marsh, Murayama, \& Goetz, 2017; Pekrun, Elliot, \& Maier, 2009). 
Many concepts studied in tandem with academic success have positive emotion as an integral feature. School engagement incorporates not only motivation and involvement, but the experience of connectedness and flow (Upadyaya \& Salmela-Aro, 2013). Rannelluchi, Hall, and Goetz (2015) addressed "learning-related emotions" and emphasized that enjoyment as essential to the development of both mastery orientation and achievement goals. Other authors have found that emotion provides crucial guidance in mental and motivational self-regulatory processes (Mega et al, 2014).

Positive classroom environments, where children feel physically and psychologically safe, allow children to perform academically and socially at higher levels (Frenzel, Pekrun, \& Goetz, 2007; Sandilos, Rimm, \& Cohen, 2017). Being physically safe in a classroom is readily obvious when the environment is free of unnecessary clutter and hazards such as chemicals or broken glass or some other environmental hazard. To be psychologically safe, however, children must be able to perform without fear of being belittled or harassed by their classmates or their teachers. They need to feel as if they belong in the classroom with their peers, and that they have social value, or relevance (Beamon, 2001; Mendler, 2000; Uzair-ul-Hassan, Farooq, Akhtar, \& Parveen, 2017). Further, belongingness, described as a sense of being a valued member of a group, may be particularly important for children with other risk factors and be a protective factor against later school dropout (Booker, 2004). Feedback on achievement and social reactions to achievement by significant others relates to students' enjoyment of learning and hope for success, or positive emotion, and to anger, hopelessness, and boredom amongst secondary school and university students (Bergin, 2016; Pekrun et al., 2002; Uzair-ul-Hassan et al. 2017).

Outside the home, the school is often a primary environment that shapes children's sense of worth as it is reflected in the manner in which teachers and peers relate to them. Children seek to belong to social groups and to be accepted by those within those groups (Mouratidis \& Sideridis, 2009; Wentzel, 2003). When children belong socially to groups, and have relevance within those groups, they will behave in ways that benefit those groups and are expected by those groups. They are members of a learning community. Additionally, young children look to significant adults, including teachers, to provide them with models on how to behave in given social conditions and to protect them from those things that, for a child, are scary or harmful, such as aggressive and abusive classmates (Platten, Hernik, Fonagy, \& Fearon, 2010). Positive classroom environments that work to eliminate fear and include belongingness, accomplishment, and self-worth all contribute to positive emotion.

Not surprisingly then, a number of intervention strategies to improve student academic functioning target the enhancement of positive emotional experiences at school. Among the reasons to choose such interventions is the relative ease of implementation compared to other known factors that improve the school experience, those that would increase socioeconomic indicators, increase one-onone contact with teachers, reduce classroom size, or improve school resources (Patton et al, 2006).

In particular, lesson-style classroom interventions of children's socioemotional skills have been demonstrated to be efficacious. Due to the interrelated nature of behavioral, cognitive, and emotional competencies, the outcomes of such interventions include reduced disruptive behavior and, as a corollary, increased academic achievement (Durlak, Weissberg, Dymnicki, Taylor, \& Schellinger, 2011). In addition, students who receive such skills training do better on tests of emotional competence, including improved attitudes toward self, and concomitantly lowered emotional distress and conduct problems (Arda \& Okac, 2012; Greenberg et al., 2003; Zins, Weissberg, Wang \& Walberg, 2004). Fewer studies have examined the effects of classroom based emotional interventions on children's attitudes toward specific classmates. 
Evidence points to the fact that a sense of social connectedness is sufficient motivation to pursue and persist at academic tasks (Walton, Cohen, Cwir, \& Spencer, 2012). Increasing social connections among learners is thought to lead to improved school outcomes (Wentzel \& Wigfield, 2007). For example, students with high peer orientation, or positive recognition by their peers, showed higher achievement scores than did children with low peer orientation (Hancock, 2004).

The Promoting Alternative Thinking Strategies (PATHS) curriculum has been used for targeted improvement in children's emotional functioning, has been recognized as a model program for use with elementary school students by the National Registry of Effect Programs and has been shown to be effective not only for improving children's emotional regulation, but in reducing problem behaviors, peer aggression, conduct problems, and hyperactivity (Schonfeld et al., 2015). As a side effect, the PATHS curriculum also impacts other classroom behaviors. It is generally adopted on a whole-school basis and is implemented over years (Honess \& Hunter, 2014). The PATHS curriculum stresses a close adherence to manualized intervention.

Teachers' perception of imposed curricula may also impede the incorporation of explicitly prosocial lessons. For example, teachers who were unfamiliar with the PATHS curriculum reported skepticism regarding its proposed efficacy. They also felt it required a strict adherence that included a particular start date (i.e., the beginning of the school year) and continuous prioritization by the school administrators. However, after the intervention had been applied, these same teachers were very positive in their perceptions of classroom changes, including children's timing to self-calm, vocalization of feelings, and increased emotional vocabulary (Honess \& Hunter, 2014).

An issue related to the acceptance by teachers of a prestructured curriculum is the likelihood that teachers will incorporate the principles of that curriculum into their individualized approaches. The adoption of positive socioemotional practices in the classroom may be particularly important because students' evaluations of their peers tend to mirror those of the teacher (Hendrickx, Mainhard, Oudman, Boor-Klip, \& Brekelmans, 2017). One avenue to facilitating the use of these principles in the classroom may be to build socioemotional training into the curriculum for student teachers with the requirement that they incorporate socioemotional features into their lesson planning. The efficacy of abbreviated PATHS curriculum has been demonstrated in kindergarten classrooms (Gibson, Werner, \& Sweeny, 2015), indicating that the full implementation of the program may not be necessary to see benefits.

Moreover, the incorporation of socioemotional reminders toward class inclusion, acceptance, and belonging may act on teachers as well as students. It has been demonstrated that when teachers positively reframe student issues, teachers show increased positive and decreased negative emotion in the classroom; this, in turn, directly impacts students' experiences (Jiang, Vaurus, Volet, \& Wang, 2016). Teachers play a pivotal role in establishing classroom environments that are both supportive and structured to elicit competency from children (De Kruif, McWilliam, Ridley, \& Wakely, 2000). Young children look to teachers to provide them with models on how to behave in given social conditions and to protect them from those things that, for a child, are scary or harmful, such as aggressive and abusive classmates. Thus, school is often a primary environment shaping a child's sense of self-worth via the manner in which teachers and peers relate to them (Hendrickx et al., 2017; Mouratidis \& Sideridis, 2009; Wentzel, 2003).

Because children must be able to perform without fear of being belittled or ostracized (Frenzel et al., 2007), our target outcome was the increase in a sense of belongingness in the classroom with peers, and thus, social value or relevance (Beamon, 2001; Mendler, 2000). The focus of this study was threefold. First, we wished to determine if teachers' lessons incorporating the rudiments of the PATHS socioemotional lessons, those that promote positive emotion, and thus prosocial behavior, would have an effect in increasing social status of students who might be considered "social outliers" 
by their peers, as measured by nominations from their peers for participation in various activities. Second, we hypothesized that teachers' evaluations of observable classroom behaviors in their students' intellectual performances and social skills, as well as their perception of students who were "well rounded," would compare favorably to children's nominations of their classmates for various social interactions. Finally, we tested whether repeated exposure to the PATHS principles in the classroom would be a factor. Thus, we varied the number of prosocial lessons taught: one, two or three lessons.

\section{Method}

\section{Participants}

Four grade schools in the southeastern United States gave permission for seven first-grade classrooms to participate in this study; 142 first-graders were given school permission to participate. Six classrooms $(n=121)$ received prosocial lessons from six teacher candidates studying in the Early Education Program at a nearby university. A seventh classroom was used as a comparison group ( $n$ $=21)$. The ethnic composition of the total sample consisted of African American $(n=79)$ and Caucasian $(n=63)$. Two children did not receive parental permission and were thus excluded from measurement although they did receive the prosocial lessons as part of the planned, expected inclusion of teacher candidate lessons to the classroom. In addition, four students provided data at either Time 1 or Time 2, but not both times, and were therefore excluded from the analysis; 136 children were assessed both at Time 1 and Time 2. This sample was composed of 69 girls and 67 boys ( $M_{\text {age }}=7.19$ years, i.e., 86.32 months, $S D=4.79$; Table 1$)$. Teacher's evaluations resulted in measures for 124 students. No differences were found between this sample and the primary sample (i.e., those from whom Time 1 and Time 2 data was obtained).

Table 1. Analysis Sample

\begin{tabular}{lc}
\hline Participants & $\boldsymbol{n}$ \\
\hline Initial sample & 142 \\
African American & 79 \\
Caucasian & 63 \\
Primary sample & \\
Totalb $\left(M_{\text {age }}=86.32\right.$ months $)$ & 136 \\
Female & 69 \\
Male & 67 \\
\hline
\end{tabular}

a Participants measured at both Time 1 and Time $2 .{ }^{\mathrm{b}} n=6$ subjects excluded from measurement because of lack of parental permission for participation $(n=2)$, or for lack of data at either Time 1 or Time $2(n=4)$ due to absence.

\section{Procedure}

\section{Prosocial Lessons}

The PATHS curriculum was developed to enhance socioemotional understanding in the classroom. The PATHS program is currently marketed as a preventative, intervention program appropriate for use across a range of categories (Kelly, Longbottom, Potts, \& Williamson, 2004). The categories include fostering positive classroom environment; animals; basic feelings; turtle technique review; and sharing, caring, and friendship. The PATHS evaluation kit is based on the ABCD (i.e., AffectiveBehavioral-Cognitive-Dynamic) model, with the primary focus being the developmental integration of affect, the vocabulary of emotion, and cognitive understanding as they relate to social and emotional competence (Kusche \& Greenberg, 1994). Essentially, the model allows for children to become cognitively aware of their own emotions and behaviors through appropriate language; by 
becoming cognitively aware, they can then begin to act on these appropriately in given social settings.

The six teacher candidates were provided training in PATHS prior to lesson development and teaching. The training provided the teacher candidates with techniques for working with young children in two of the five categories: fostering positive classroom environments and sharing, caring, and friendship. This training was conducted by a certified PATHS trainer over a 4-hr period and included role playing activities with PATHS materials while working with peers.

Following the training, six lessons were developed by the teacher candidates that addressed the two particular PATHS unit themes. The topics of the developed lessons were respect for others, trust in others with whom one works, individual uniqueness and strengths, cooperation with others, acceptance and fair treatment of others, and teamwork. The lessons were taught such that two classes received one lesson each, three classes received two lessons each, and one class received three lessons. No single lesson was taught twice in any classroom. A seventh class was used as a comparison group, and no prosocial lessons were taught in this classroom. All participating classes were randomly selected to determine how many lessons would be taught in each, including the comparison class.

\section{Measures}

\section{Children's Sociometric Nomination of Peers}

Prior to the teaching of any of the lessons, the children from each of the first-grade classrooms involved in the study were interviewed individually and were asked to respond to four questions by graduate students from the psychology department of the same university. The children were directed to nominate their classmates based on the following questions, and their responses were recorded (Time 1): (a) "name the student whom you most admire," (b) "If you had a birthday party and could invite three people from your class, who would you invite?" (c) "Name three students you enjoy playing with on the playground," and (d) "Name four students you enjoy working with in the classroom." Following the teaching of the lessons by the student teacher candidates, the children were again asked to respond to the same four questions by a different group of graduate students from the psychology department, and their responses were again recorded (Time 2).

\section{Teacher's Sociometric Nomination of Students}

Teachers completed a measure asking for their top four students in the areas of intellectual performance, social skills, and those who they felt were "well rounded." These categories were summed to yield a Favorable Adjustment subscale. All three variables were submitted to a Pearson product-moment correlation, which showed that all three were statistically significantly and positively related (intercorrelation range $=0.21-0.28$, Cronbach's $\alpha=0.50$ ).

In addition, teachers identified the students within their classrooms whom they considered to be aggressive, impulsive, withdrawn and needy. The teacher responses were intended to sum to yield a Poor Adjustment subscale, but visual inspection showed that they broke out into two subscales: impulsive and aggressive were statistically significantly negatively correlated with withdrawn and needy (range $=-0.21$ to $-0.23, p<.01$ ). The two subscales were named Externalizing Adjustment (Impulsive and Aggressive were positively correlated, $r=0.45, p<.01$; Cronbach's $\alpha=0.62$ ) and Internalizing Adjustment (withdrawn and needy were positively correlated, $r=0.22, p=.03$; Cronbach's $\alpha=0.35$ ). 


\section{Data Management}

\section{Scaling the Data}

For each child, a tally was taken of the total number of nominations given to them by other children, at both Time 1 and Time 2. This included the number of times that a student received a nomination as a best friend by a classmate, the number of times he or she received a nomination as desirable to invite to a party, the number of times he or she received a nomination for playground play, and the number of times he or she received a nomination to be with in the classroom. Next, we scaled each child's nomination by the number of children in the particular classroom. This ensured that children's scores in large classrooms would not be inflated relative to the nominations of children in small classrooms and made children's nominations comparable across schools. The Pearson productmoment correlation of Time 1 scaled nominations to Time 2 was statistically significant, $r=0.76, d f$ $=116, p<.01$.

\section{Change Scores in Popularity From Time 1 to Time 2}

A change score was derived by subtracting Time 1 from Time 2, resulting in a metric that would indicate an increase in nominations as a positive number. For this change score, both skewness (0.24) and kurtosis (0.34) were observed to be within acceptable limits.

\section{Classifying Children According to Social Status}

We assigned each student a status based on a standardized scaled total nomination score. These groups were (a) $1 S D$ below average (i.e., at least $1 S D$ below the mean; $n=21$ ), (b) below average (i.e., between the mean and $1 S D$ below; $n=54$ ), (c) above average (i.e., between the mean and $1 S D$ above; $n=38$ ), and (d) $1 S D$ above average (i.e., at least $1 S D$ above the mean; $n=23$ ). The rationale for this categorization was to identify children in the highest and lowest social categories, relative to their average peers.

\section{Results}

\section{Preliminary Analyses}

We first determined whether the demographic variables of age, gender, and ethnicity played a role on the studies outcome. We conducted a univariate analysis of variance (ANOVA) to examine effects on change in numbers of nominations from Time 1 to Time 2 depending upon gender. There were no group differences depending on gender, $F(1)=0.648, p=.42$. In addition, there was no significant interaction between gender and the number of lessons, $F(2,116)=0.18, p=.84$, or between gender and the social status of the child, $F(4,112)=0.38, p=.63$. Similarly, no group differences depended upon ethnicity, $F(3,115)=0.074, p=.97$, on the interaction tests for ethnicity and numbers of lessons, $F(6,112)=1.05, p=.40$, or between ethnicity and social status, $F(6,112)=0.89, p=.45$. Finally, a Pearson product-moment correlation comparing the scaled nominations at Time 1 and Time 2 was significant, $r=0.73, d f=135, p<.001$.

\section{Comparing Children's and Teacher's Student Ratings}

We were interested in examining how a teacher's evaluations of observable classroom behaviors would compare with children's nominations of their classmates. First, as a validation check, we report that students who were given only good ratings by their teacher received the highest number of nominations $(M=0.76, S D=0.06)$ by their classmates, $F(3,120)=9.005, p<.01, \eta^{2} \mathrm{p}=0.18$. Tukey's honest significant difference test revealed that this group receiving rating on only positive traits differed from children in the other three groups: negative traits only $(M=0.43, S D=0.05)$, positive and negative traits $(M=0.44, S D=0.09)$, or no trait ratings from teachers $(M=0.38, S D=$ 0.06). As may be seen by inspecting the standard error of measurement bars in Figure 1, the latter 
three groups did not differ from one another in numbers of nominations from their classmates. This was determined by a Kruskal-Wallis test of ranked groups $(H)$, due to the appropriateness of a nonparametric comparison of groups using these data.

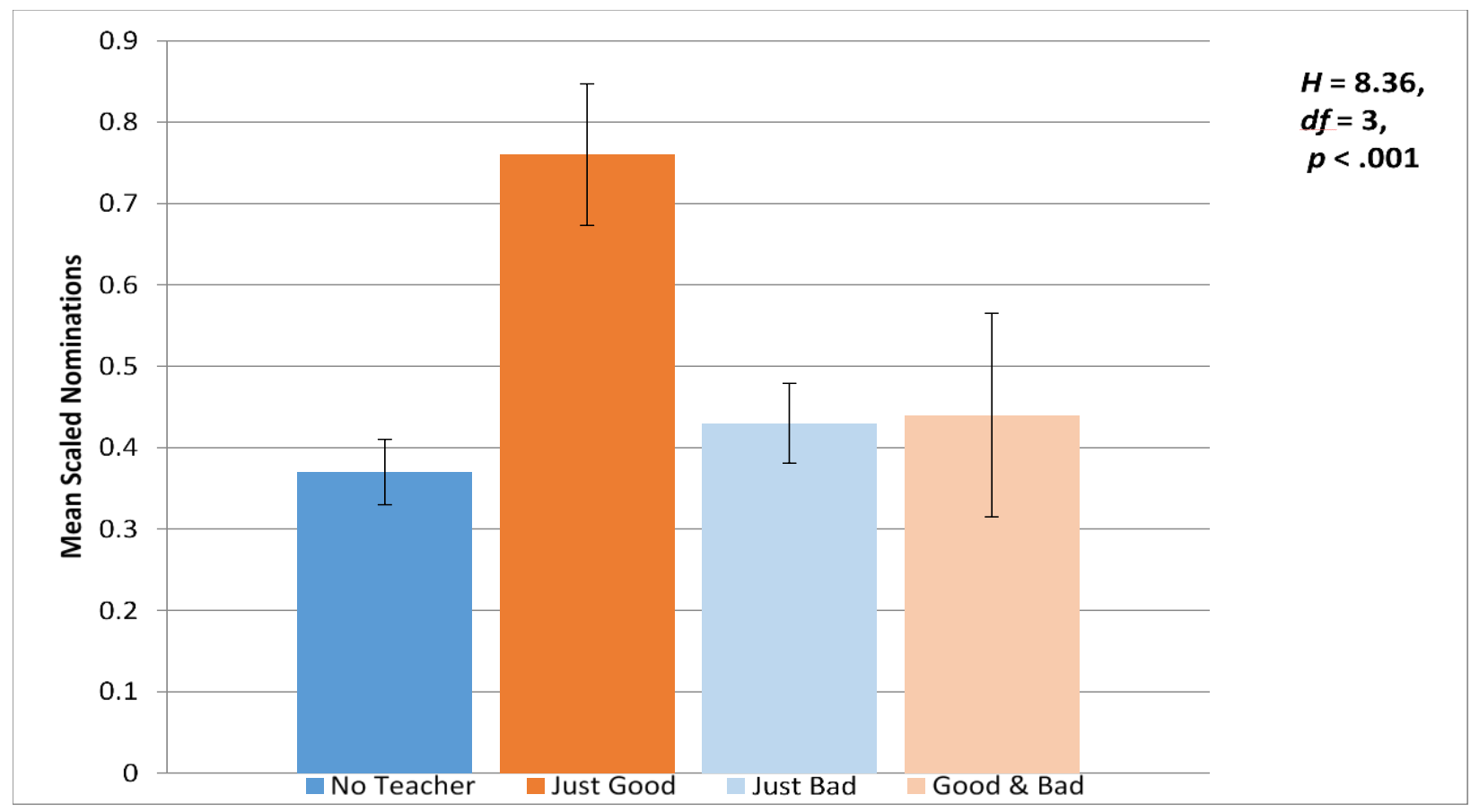

Figure 1. Mean Differences in Children's Sociometric Nominations According to Teacher Categorization. Error bars represent SEM. $\mathrm{H}=$ Kruskal-Wallis test of ranked groups.

We implemented Pearson product-moment correlations to conduct more fine-grained analyses on teacher's rating of observable traits. As shown in Table 2, children's nominations of classmates as most liked, as likely to be invited to play on the playground, and as likely to work with in the classroom were correlated with the teacher's positive ratings. Moreover, participants were less likely to gain peer nominations if they were rated by teachers as having internalizing tendencies (being withdrawn and/or needy). However, externalizing tendencies as rated by teachers (impulsive and/or aggressive) were not related to numbers of nominations won from classmates.

Table 2. Pearson Product-Moment Correlations Between Teachers' Ratings of First-Grader Characteristics and First-Graders' Ratings of Classmates as a Desirable Companion in Multiple Contexts ( $\mathrm{N}=136)$

\begin{tabular}{|c|c|c|c|c|c|c|c|}
\hline Measured Variable & 1. & 2. & 3. & 4. & 5. & 6. & 7. \\
\hline 1. Positive TR & 1 & & & & & & \\
\hline 2. Externalizing TR & $-.22^{*}$ & 1 & & & & & \\
\hline 3. Internalizing TR & $-.27 * *$ & -.007 & 1 & & & & \\
\hline 4. $\mathrm{CN}$ to be best friend & $.32^{* *}$ & -.11 & $-.23^{*}$ & 1 & & & \\
\hline 5. CN to invite to party & $.51 * *$ & -.04 & $-.29 * *$ & $.68^{* *}$ & 1 & & \\
\hline $\begin{array}{l}\text { 6. CN to play on } \\
\text { playground }\end{array}$ & $.38^{* *}$ & -.03 & $-.23^{*}$ & $.56^{* *}$ & $.58 * *$ & 1 & \\
\hline $\begin{array}{l}\text { 7. CN to work with in } \\
\text { classroom }\end{array}$ & $.49^{* *}$ & -.09 & $-.29 * *$ & $.58 * *$ & $.63^{* *}$ & $.40^{* *}$ & 1 \\
\hline
\end{tabular}

Note. $\mathrm{TR}=$ teacher rating; $\mathrm{CN}=$ child nomination of classmates.

${ }^{*} p<.05 .{ }^{* *} p<.001$. 


\section{Outcomes of the PATHS Training and Prosocial Lessons}

Our findings did not support our hypothesis that the number of prosocial lessons would be linked to greater class nominations for social outliers, $F(2,116)=0.376, p=.69$. However, via one final oneway ANOVA, we showed that, overall, children with the least social visibility increased their number of nominations at Time 2 , whereas the most popular children showed the highest decrease, $F(3,115)$ $=9.88, p<.01$. Figure 2 shows gains and losses in the closed system of the classroom. Inspecting the bars for the groups who received prosocial lessons, it can be seen that social outliers ( $1 S D$ below) garnered gains from the most popular children (1 SD above), In other words, following the teaching of the prosocial lessons, the initially least nominated children gained in number of peer nominations, whereas the initially most nominated children decreased in the number of peer nominations.

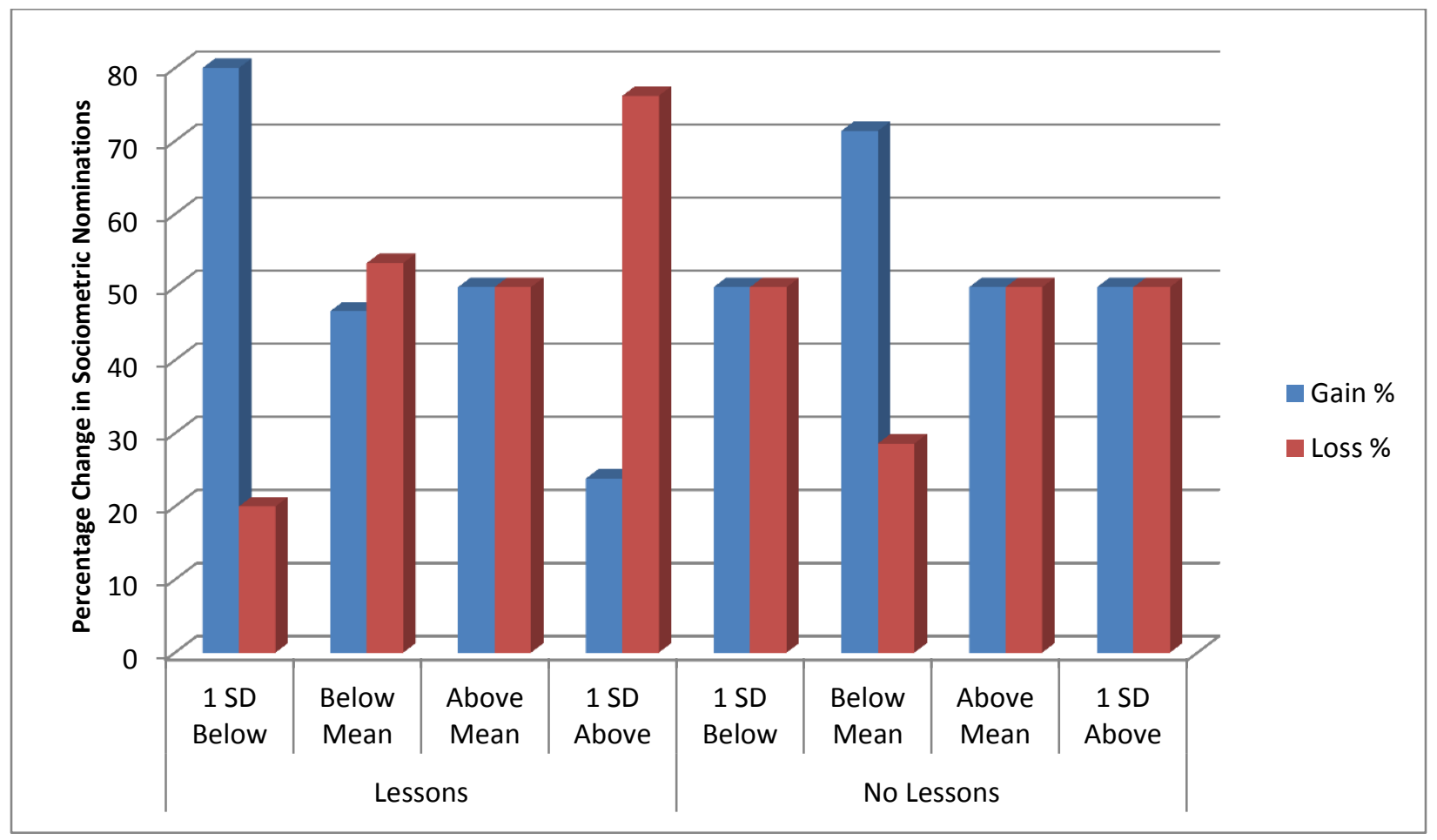

Figure 2. Mean Differences in Children's Sociometric Nominations According to Teacher Categorization

A post hoc comparison of statistically significant differences among these groups using Tukey's honest significant difference test revealed that the group of children whose popularity placed them more than $1 S D$ above the mean had a statistically significant lower change score $(M=-0.265, S D=$ $0.33)$ than did children in the above-average group, $(M=0.0005, S D=0.25)$, children in the belowaverage group, $(M=0.008, S D=0.21)$, or children who were more than $1 S D$ below the mean on popularity, $(M=0.114, S D=0.16)$. The latter three groups did not differ from one another in change score. These comparisons are shown in Table 3. 
Table 3. Percentage of Students Included in Each Group of the Loglinear Analysis

\begin{tabular}{|c|c|c|c|c|c|c|c|c|}
\hline \multirow[b]{2}{*}{$\begin{array}{l}\text { Pre- and Posttest } \\
\text { Data }\end{array}$} & \multicolumn{4}{|c|}{ Lesson } & \multicolumn{4}{|c|}{ No Lesson } \\
\hline & $\begin{array}{c}1 S D \\
\text { Below }\end{array}$ & $\begin{array}{l}\text { Below } \\
\text { Mean }\end{array}$ & $\begin{array}{l}\text { Above } \\
\text { Mean }\end{array}$ & $\begin{array}{c}1 S D \\
\text { Above }\end{array}$ & $\begin{array}{c}1 S D \\
\text { Below }\end{array}$ & $\begin{array}{l}\text { Below } \\
\text { Mean }\end{array}$ & $\begin{array}{l}\text { Above } \\
\text { Mean }\end{array}$ & $\begin{array}{c}1 S D \\
\text { Above }\end{array}$ \\
\hline Pretest & & & & & & & & \\
\hline $\begin{array}{l}\text { Initial inclusion } \\
\text { Posttest }\end{array}$ & $17 \%$ & $40 \%$ & $26 \%$ & $17 \%$ & $12 \%$ & $38 \%$ & $31 \%$ & $19 \%$ \\
\hline Gain & $28 \%$ & $36 \%$ & $27 \%$ & $9 \%$ & $18 \%$ & $45 \%$ & $27 \%$ & $9 \%$ \\
\hline Loss & $7 \%$ & $40 \%$ & $27 \%$ & $26 \%$ & $25 \%$ & $25 \%$ & $37 \%$ & $13 \%$ \\
\hline
\end{tabular}

Note. Groups formed by standard deviations of the change scores in the scaled nominations (i.e., best friend, invite to party, play with on playground, work with in classroom).

We interpreted the data to show that the social outlier group (i.e., $1 S D$ below) gained positive sociometric nominations "at the expense of" the popular group of children (i.e., $1 S D$ above), a group who would suffer no adverse effects from "sharing" their votes. To verify that this effect was significant, we tested whether the gains and losses described above were statistically significant via a hierarchical loglinear analysis. As may be seen in Table 4 (over and above the fact that postlesson gains and losses represented a statistically significant change from the prelesson measurement time), a significant three-way interaction validated a greater equity of votes in the classroom after the prosocial lessons.

Table 4. Likelihood and Parameter Estimates for the Hierarchical Loglinear Analyses

\begin{tabular}{lcc}
\hline Step & Likelihood Estimate & Partial $\chi^{2}$ \\
\hline Three-way interaction & $\chi^{2}(3)=3.28, p=.35$ & \\
Lower order estimates & & $-3.17^{* *}$ \\
Gain and Loss $\times$ Groups & & -0.50 \\
Gain and Loss $\times$ Lesson (yes or no) & & $2.23^{*}$ \\
Gain and Loss & & \\
\hline
\end{tabular}

${ }^{*} p<.05 . * * p<.001$.

\section{Determining Source of Change}

We also examined the context of the change because we wished to see if the increase in nominations of the least popular group would be specific to a particular social context. In a one-way ANOVA, we compared the average number of nominations of each group of children in each of the environments we had asked about: invite to party, play with on playground, or work with in classroom. Although there was no change in the nominations by status group to invite to a party, $F(3,115)=1.66, p=.18$, or play with on the playground, $F(3,115)=1.85, p=.15$, there was a statistically significant difference in the means of the status group for work with in class, $F(3,115)=3.46, p=.02$.

As a final analysis, we examined the context in which the socially invisible children increased in nominations. As may be seen in Figure 2, it was in the context of the classroom that these children, as well as those who were moderately popular, increased their nominations at Time 2 over Time 1.

\section{Discussion}

This study examined whether teacher perceptions of student intellectual performance, social skills, and well-roundedness and positive social recognition by peers would be affected by the teaching of prosocial lessons. The classroom environment is one in which students spend a great deal of time 
interacting with others, and if the environment is socially positive for learners, then it becomes a positive learning environment (Frenzel et al., 2007)

In this study, the authors did not find group differences based on gender or ethnicity when compared with the number of lessons taught and social status as determined by children's nominations. This does not mean that children do not recognize the differences between boys and girls or the ethnicity of other children. Instead, this may mean that children who received only positive ratings by their teachers received the highest number of nominations from other children for social interactions, as opposed to those children who received both positive and negative, negative, or no trait ratings from teachers. There is an implication here that children can determine the difference between positive and negative traits in other children that match the perceptions of their adult teachers or that children are able to read the subtle cues of the teacher that communicate a preference for positive traits in others and thus look to the teacher in forming preferences for their classmates. This would tend to reinforce the notion children are able to pick up on subtle cues that implicitly distinguish groups from each other (Heiphetz, Spelke, \& Banaji, 2013). It could also be possible that students are able to intuit their teachers' perceptions of what is most desirable in student behavior, possibly through verbal and nonverbal communication clues exhibited by the teacher, and would thus wish to associate with those whom the teacher finds most favor (Davis, 2003; Hendrickx et al., 2017; Manke, 1997; Nelson \& Russell, 2012; Tracy, Robins, \& Lagattuta, 2005; Shields, Engelhardt, \& Ietswaart, 2012). The data reveal that the number of nominations of children by their peers who were identified by the teacher as having only negative traits, both positive and negative traits, or no identified traits by the teacher was not statistically significant.

The study also found that there was a correlation between teachers' positive ratings of their students and children's nominations of classmates for best liked, for playing with on the playground, and for working with in the classroom. But children who were identified by the teacher as having internalizing tendencies (withdrawn and needy) were less likely to be nominated by their classmates for any of the activities. One would have to question, again, whether this was because of the influence of teacher perceptions of students on other children or if children themselves were capable of recognizing the internalizing tendencies in others and found them to be disagreeable. Perhaps it is both. But there is a strong implication that the teacher is influential in how children are socially regarded by their peers in the classroom.

Impulsivity and aggressiveness are most often associated with action, whereas withdrawn and needy are traits that could be described as passive personalities. It could be that children want to be associated with others who are at least involved and doing something, whereas the idea of being associated with children who are timid or quiet is not very exciting. If both are true, then, socially, it would be beneficial to structure a classroom learning environment where all students were encouraged to be active participants in the learning process.

The number of prosocial lessons taught to students in a given classroom was not statistically relevant to change in popularity, as evidenced by the number of nominations garnered at Time 2 in the study. But the authors found that teaching one lesson was beneficial in helping to balance the overall popularity playing field within the context of the classroom. In the classrooms where lessons were taught, those children who were identified as social outliers (the $1 S D$ below average group) at Time 1 gained in nominations at Time 2, whereas children in the highest social category (the $1 S D$ above average group) at Time 1 lost nominations at Time 2 . This was opposed to what was found in the control classroom, where no prosocial lessons were taught and no significant change in nominations occurred at Time 2 for the children in the $1 S D$ above average group or the $1 S D$ below average group. It would seem making children aware that others have social value within the context of the classroom allows for a more balanced, prosocial environment for all the children. This awakening can be accomplished through the power of one (or more) prosocial lessons. 
While we stress that the teacher plays a substantial role in helping children formulate concepts about what is and is not prosocial behavior within the classroom, and that she or he may be responsible for much of the social perception that other children may have on a student or group of students, there are other factors that will most certainly influence social perceptions, including familial and economic influences outside the classroom. This study did not measure any variables that spoke to these influences. Also, while there was a classroom teacher for each of the classrooms involved in the study, there were six teacher candidates who taught the lessons in these classrooms. They did not have the familiarity with the children as did the classroom teachers and vice versa. Does this matter? In other words, for the children, did this tend to make the lesson or lessons more relevant or less relevant to them, given that they did not know who these six individuals were who were teaching them? Perhaps if the classroom teachers had taught these lessons, rather than the six teacher candidates, there may have been a greater impact on the children. This would be due, at least in part, to the classroom teachers' experience in classroom management techniques, experience in teaching, and relationship with the children whom they teach. Also, is it possible that teacher candidate attitudes about the lessons they taught and the schools they were in, as well as their perceptions on the children whom they taught, might have some impact on the value of the lessons themselves.

Ultimately, the results of this study indicate that prosocial lessons do have value in lifting up those children in a classroom where they may be socially isolated or forgotten. And although we saw that the most popular of the children lost some of their popularity in terms of losing nominations at Time 2 , none of them were affected to the point where this became a negative impact on them personally. They were not aware of who did or did not nominate them at either Time 1 or Time 2 . The classrooms became more balanced socially, so that all children had a better chance to belong equally with their classmates.

\section{References}

Arda, T. B., \& Okac, S. (2012). Social competence and promoting alternative thinking strategies: PATHS preschool curriculum. Educational Sciences: Theory \& Practice, 12, 2691-2698.

Beamon, G. W. (2001). Making classrooms "safe" for adolescent learning. Paper presented at the 53rd annual meeting of the American Association of Colleges for Teacher Education, Dallas, TX, March 1-4. Retrieved from https://files.eric.ed.gov/fulltext/ED451185.pdf

Bergin, D. A. (2016). Social influences on interest. Educational Psychologist, 51, 7-22. doi:10.1080/00461520.2015.1133306

Booker, K. C. (2004). Exploring school belonging and academic achievement in African American adolescents. Curriculum and Teaching Dialogue, 6, 133-143.

Chen, L., Bae, S., Battista, C., Qin, S., Chen, T., Evans, T. M., \& Menon, V. (2018). Positive attitude toward math supports early academic success: Behavioral evidence and neurocognitive mechanisms. Psychological Science, 29, 390-402. doi:10.1177/0956797617735528

Cohen, L., \& Huppert, J. D. (2018). Positive emotions and social anxiety: The unique role of pride. Cognitive Therapy and Research, 42, 524-538. doi:10.1007/s10608-018-9900-2

Davis, H. A. (2003). Conceptualizing the role and influence of student-teacher relationships on children's social and cognitive development. Educational Psychologist, 38, 207-234.

De Kruif, R. E. L., McWilliam, R. A., Ridley, S. M., \& Wakely, M. B. (2000). Classification of teachers' interaction behaviors in early childhood classrooms. Early Childhood Research Quarterly, 25, $247-268$. 
Durlak, J. A., Weissberg, R. P., Dymnicki, A. B., Taylor, R. D., \& Schellinger, K. B. (2011). The impact of enhancing students' social and emotional learning: A meta-analysis of school-based universal interventions. Child Development, 82, 405-432.

Frenzel, A. C., Pekrun, R., \& Goetz, T. (2007). Perceived learning environment and students' emotional experiences: A multilevel analysis of mathematics classrooms. Learning and Instruction, 17, 478-493.

Gibson, J. E., Werner, S. S., \& Sweeny, A. (2015). Evaluating an abbreviated version of the paths curriculum implemented by school mental health clinic. Psychology in the Schools, 52, 549561.

Greenberg, M. T., Weissberg, R. P., O’Brien, M. U., Zins, J. E., Fredericks, L., Resnik, H., Elias, M. J. (2003). Enhancing school-based prevention and youth development through coordinated social, emotional, and academic learning. American Psychologist, 58, 466-474.

Hancock, D. (2004). Cooperative learning and per orientation effects on motivation and achievement. Journal of Educational Research, 97, 159-166.

Heiphetz, L., Spelke, E. S., \& Banaji, M. R. (2013). Patterns of implicit and explicit attitudes in children and adults: Tests in the domain of religion. Journal of Experimental Psychology: General, 142, 864-879. doi:10.1037/a0029714

Hendrickx, M. M. H. G., Mainhard, T., Oudman, S., Boor-Klip, H. J., \& Brekelmans, M. (2017). Teacher behavior and peer liking and disliking: The teacher as a social referent for peer status. Journal of Educational Psychology, 109, 546-558.

Honess, A., \& Hunter, D. (2014). Teacher perspectives on the implementation of the PATHS curriculum. Educational Psychology in Practice, 30, 51-62.

Jiang, J., Vaurus, M., Volet, S., \& Wang, Y. (2016). Teachers' emotions and emotion regulation strategies: Self- and students' perceptions. Teaching and Teacher Education, 54, 22-31.

Kelly, B., Longbottom, J., Potts, F., \& Williamson, J. (2004). Applying emotional intelligence: Exploring the Promoting Alternative Thinking Strategies curriculum. Educational Psychology in Practice, 20, 221-240.

Kusche, C., \& Greenberg, M. (1994). PATHS: Promoting alternative thinking strategies. South Deerfield, MA: Developmental Research Programs.

Lewis, A. D., Huebner, E. S., Malone, P. S., \& Valois, R. F. (2011). Life satisfaction and student engagement in adolescents. Journal of Youth and Adolescence, 40, 249-262. doi:10.1007/s10964-010-9517-6

Li, Y., \& Lerner, R. M. (2011). Trajectories of school engagement during adolescence: Implications for grades, depression, delinquency, and substance use. Developmental Psychology, 47, 233247. doi:10.1037/a0021307

Madan, C. R., Scott, S. E., \& Kensinger, E. A. (2019). Positive emotion enhances association-memory. Emotion, 19, 733-740. doi:10.1037/emo0000465

Manke, M. P. (1997). Classroom power relations : Understanding student-teacher interaction. Mahwah, NJ: Routledge.

Mega, C., Ronconi, L., \& De Beni, R. (2014). What makes a good student? How emotions, selfregulated learning, and motivation contribute to academic achievement. Journal of Educational Psychology, 106, 121-131.

Mendler, A. N. (2000). Motivating students who don't care: Successful techniques for educators: Solutions. Bloomington, IN: National Educational Service. 
Mouratidis, A. A., \& Sideridis, G. D. (2009). On social achievement goals: Their relations with peer acceptance, classroom belongingness, and perceptions of loneliness. Journal of Experimental Education, 77, 285-308.

Nelson, N. L., \& Russell, J. A. (2012). Children's understanding of nonverbal expressions of pride. Journal of Experimental Child Psychology, 111, 379-385. doi:10.1016/j.jecp.2011.09.004

Patton, G. C., Bond, L., Carlin, J. B., Thomas, L., Butler, H., Glover, S., . . Bowes, G. (2006). Promoting social inclusion in schools: A group-randomized trial of effects on student health risk behavior and well-being. American Journal of Public Health, 96, 1582-1158.

Pekrun, R., Elliot, A. J., \& Maier, M. A. (2009). Achievement goals and achievement emotions: Testing a model of their joint relations with academic performance. Journal of Educational Psychology, 101, 115-135. doi:10.1037/0013383

Pekrun, R., Goetz, T., Titz, W., \& Perry, R. P. (2002). Academic emotions in students' self-regulated learning and achievement: A program of qualitative and quantitative research. Educational Psychologist, 37, 91-105.

Pekrun, R., Lichtenfeld, S., Marsh, H. W., Murayama, K., \& Goetz, T. (2017). Achievement emotions and academic performance: Longitudinal models of reciprocal effects. Child Development, 88, 1653-1670.

Piff, P. K., \& Moskowitz, J. P. (2018). Wealth, poverty, and happiness: Social class is differentially associated with positive emotions. Emotion, 18, 902-905. doi:10.1037/emo0000387

Platten L., Hernik M., Fonagy P., \& Fearon R. (2010). Knowing who likes who: The early developmental basis of coalition understanding. European Journal of Social Psychology, 40, $569-580$.

Rannelluchi, J., Hall, N. C. \& Goetz, T. (2015). Achievement goals, emotions, learning, and performance: A process model. Motivation Science, 1, 98-120.

Sandilos, L. E., Rimm, K. S. E., \& Cohen, J. J. (2017). Warmth and demand: The relation between students' perceptions of the classroom environment and achievement growth. Child Development, 88, 1321-1337. doi:10.1111/cdev.12685

Schonfeld, D. J., Adams, R. E., Fredstrom, B. K., Weissberg, R. P., Gilman, R., Voyce, C., ... SpeeseLinehan, D. (2015). Cluster-randomized trial demonstrating impact on academic achievement of elementary social-emotional learning. School Psychology Quarterly, 30, 406420. doi:10.1037/spq0000099

Shields, K., Engelhardt, P. E., \& Ietswaart, M. (2012). Processing emotion information from both the face and body: An eye-movement study. Cognition and Emotion, 26, 699-709. doi:10.1080/02699931.2011.588691

Tracy, J. L., Robins, R. W., \& Lagattuta, K. H. (2005). Can children recognize pride? Emotion, 5, 251-257. doi:10.1037/1528-3542.5.3.251

Upadyaya, K., \& Salmela-Aro, K. (2013). Development of school engagement in association with academic success and well-being in varying social contexts: A review of empirical research. European Psychologist, 18, 136-147.

Uzair-ul-Hassan, M. U., Farooq, M. S., Akhtar, M. P., \& Parveen, I. (2017). Teachers' politeness as a predictor of students' self-esteem and academic performance. Bulletin of Education \& Research, 39, 229-243.

Villavicencio, F. T., \& Bernardo, A. B. I. (2013). Positive academic emotions moderate the relationship between self-regulation and academic achievement. British Journal of Educational Psychology, 83, 329-340. 
Walton, G. M., \& Cohen, G. L., Cwir, D., \& Spencer, S. J. (2012). Mere belonging: The power of social connections. Journal of Personality and Social Psychology, 102, 513-532.

Wentzel, K. R. (2003). Motivating students to behave in socially competent ways. Theory Into Practice, 42, 319-326.

Wentzel, K. R., \& Wigfield, A. (2007). Motivational interventions that work: Themes and remaining issues. Educational Psychologist, 42, 261-271.

Zins, J. E., Weissberg, R. P., Wang, M. C., \& Walberg, H. J. (Eds.). (2004). Building academic success on social and emotional learning: What does the research say? New York, NY: Teachers College Press.

The Journal of Educational Research and Practice provides a forum for studies and dialogue that allows readers to better develop social change in the field of education and learning. Journal content may focus on educational issues of all ages and in all settings. It also presents peer-reviewed commentaries, book reviews, interviews of prominent individuals, and additional content. The objectives: We publish research and related content that examines current relevant educational issues and processes aimed at presenting readers with knowledge and showing how that knowledge can be used to impact social change in educational or learning environments. Additional content provides an opportunity for scholarly and professional dialogue regarding that content's usefulness in expanding the body of scholarly knowledge and increasing readers' effectiveness as educators. The journal also focuses on facilitating the activities of both researcher-practitioners and practitioner-researchers, providing optimal opportunities for interdisciplinary and collaborative thought through blogging and other communications.

Walden University Publishing: http://www.publishing.waldenu.edu 